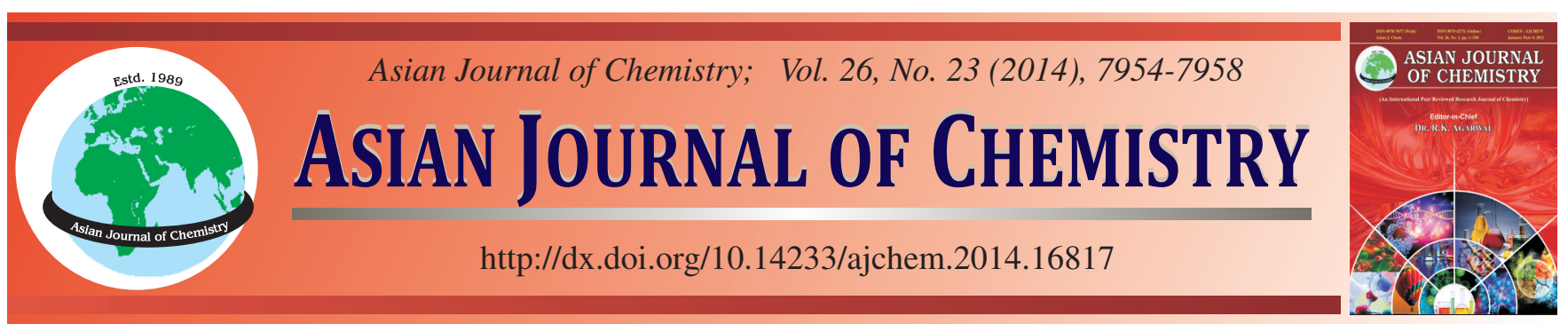

\title{
Physico-Chemical Attributes and Nutritional Ingredients of Fresh Chinese Rice Wines from Different Regions
}

\author{
Jingkai JiAo ${ }^{1,2}$, HuAXI Yi ${ }^{2}$, LANWEi Zhang ${ }^{2, *}$ and ChaOhui XuE ${ }^{2}$
}

${ }^{1}$ State Key Laboratory of Dairy Biotechnology, Dairy Research Institute, Bright Dairy and Food Co. Ltd., Shanghai 200436, P.R. China ${ }^{2}$ School of Food Science and Engineering, Harbin Institute of Technology, 73 HuangHe Avenue, Harbin 150090, Heilongjiang Province, P.R. China

*Corresponding author: Tel: +86 451 86282901; E-mail: zhanglw@ hit.edu.cn; xndxjjk@126.com

Keywords: Rice wine, Physical and chemical attributes, Amino acid, Monosaccharide, Disaccharide.

\section{INTRODUCTION}

Rice wine is a fermented beverage with high nutritious value and popular among most of Asian countries, including China, Korea, Japan, India and Thailand. Rice wine is mainly made from glutinous rice, grain or cereal, but with different name and material in different country, such as sweet fermented rice or yellow wine in China, sake in Japan and Ruou in Viet Nam. Even so, rice wine has a similar fermented process inherited from ancestors. Most rice wines are fermented under the natural circumstances with interaction of fungi, yeast and bacteria especially lactic acid bacteria, which is a complicated procedure $^{1-6}$. After the fermentation from grain or cereal, the production was obtained with non-filtration, filtration or distillation. In China, some kinds of rice wine with distillation, such as Kaoliang with a higher alcoholic content, which can reach to $40 \%$ by volume. Otherwise, we call the wine without distillation as "yellow wine" and the ethanol content ranges up to $20 \%$ by volume. Sometimes, there is fermented residue left in rice wine and only fermented for a couple of days. These rice wines are not deep fermented, which means they are fresh. We also called them sweet fermented rice or "Laozao" in China. The sweet ferm- ented rice has a lower alcoholic content about $5 \%$ by volume.
Rice wine with abundant nutritious substances in it attracts more and more investigators. Ferulic Acid, which is the basic component of the medicine to cure cardiovascular and cerebrovascular diseases and leucopenia, in rice wine was detected lately. The result showed that the concentration of ferulic acid increased during the process of fermentation ${ }^{7}$. The comparisons of amino acids between two different rice wine derived from traditional natural fermentation and pure molded mass fermentation, respectively were studied and found out that the rice wine fermented by natural environment have more abundant of amino acids ${ }^{8}$. The organic acid in this two kinds of rice wine was also detected, the result showed that the amount of organic acid in these two kinds of rice wine was equivalent and increased with time consuming 9 . And later investigations showed that there were a variety of amino acids ${ }^{10}$, a large amount kinds of sugars ${ }^{11}$, biogenic amine contents ${ }^{12}$, antioxidant activities ${ }^{13}$ and aroma compounds ${ }^{14}$ in rice wine, which determined the flavor substances, nutritious components and biologic activities of rice wine.

Nowadays, researches about Chinese rice wine are increased, but most of which were from markets. In this paper, we compared physico-chemical attributes and nutritional ingredients of nine kinds of rice wines, which were diverse in how they made and where they came from. A variety of 
analytical methods were applied in this paper to analyze the constituents in nine kinds of rice wines from different regions of China. The aim of this study was to support the evaluation of diverse functional and nutritional ingredients in traditional fermented rice wine.

\section{EXPERIMENTAL}

Nine kinds of rice wines were obtained from three provinces of China. The samples named as NA1, NA2 and NA3 were from native families in Ning'an, Heilongjiang province. The samples named as MDJ1 and MDZ2 were from native families in Mudanjiang, Heilongjiang province. The FS1 sample was from the market in Fushun, Liaoning province. The six samples which mentioned above were all liquid. The samples named as X1, X3 and X2 were from markets and families respectively in Xiaogan, Hubei province, which were semi-solid. All samples were stored at $4{ }^{\circ} \mathrm{C}$ prior to screening for their functional properties.

Physico-chemical analysis: Semi-solid samples were analyzed after centrifuged at $300 \times \mathrm{g}$ for $1-2 \mathrm{~min}$ in a centrifuge (Sigma 3-30k, SIGMA Laborzentrifugen GmbH, Germany) and the supernatant was obtained to be the objects of study in the following experiments. Total solid content was determined using the GB/T method (GB/T 13662-2008). Electric constant temperature drying oven (202-3A, Taisite, China) was applied at $103 \pm 2{ }^{\circ} \mathrm{C}$ for $4 \mathrm{~h}$ to obtain the constant weight of samples. The acidity of rice wine was measured by acid-base titration method. 2 to $5 \mathrm{~mL}$ each of samples was placed in a triangular flask with 250 volume, using phenolphthalein as an acid-base indicator. Quantitative analysis was used by definite volumes of base standard solutions $\left(0.9995 \mathrm{~mol} \mathrm{~L}^{-1}\right)$. Acidity quantity was calculated by the formula of GB/T 15038-2006 method. Alcoholic content was determined by an alcohol meter. Accurately $100 \mathrm{~mL}$ sample was placed in a 500 volume of distilling flask and then washed with $50 \mathrm{~mL}$ distilled water. The total samples with water were distilled until the volume of liquid condensed from vapor in distillation reached $100 \mathrm{~mL}$. The distilled liquid was held at a temperature of $20 \pm 0.1{ }^{\circ} \mathrm{C}$ for $0.5 \mathrm{~h}$. Then the distilled liquid was performed in $100 \mathrm{~mL}$ graduated cylinder and the amount of ethanol was measured by alcohol meter, the temperature was also measured at the same time. The alcohol result was translated into the temperature of $20{ }^{\circ} \mathrm{C}$ according to the sheet of transform (GB/T 15038-2006).

Total protein content determination: Protein content was determined by the Bradford protein assay $15.1 \mathrm{~mL}$ of each sample with $10 \times$ dilution was placed in a $20 \times 200 \mathrm{~nm}$ glass tube and added $5 \mathrm{~mL}$ of protein reagent, which contained $0.01 \%$ (w/v) Coomassie Brilliant Blue G-250 (Sigma, Germany), $4.7 \%$ $(\mathrm{w} / \mathrm{v})$ ethanol and $8.5 \%(\mathrm{w} / \mathrm{v})$ phosphoric acid. Then protein concentrations were determined by the absorbance at $595 \mathrm{~nm}$ using a spectrophotometer (analytikjena SPECORD/200, analytikjena, Germany). A standard curve was prepared using bovine serum albumin as standard solution.

Amino acids determination: Free amino acids were analyzed by an amino acid analyzer (L-8800, Hitachi Ltd., Japan). $2 \mathrm{~mL}$ of each sample was placed in a flask with the volume of $10 \mathrm{~mL}$ and then added $2 \mathrm{~mL}$ of aqueous solution of sulfosalicylic acid $(50 \mathrm{~g} / \mathrm{L})$. The flask was swirled for $30 \mathrm{~s}$ and made up to $10 \mathrm{~mL}$ with $\mathrm{HCl}$ solution $(0.02 \mathrm{~mol} / \mathrm{L})$ after staying for $0.5 \mathrm{~h}$. Then the mixture was filtered through a 0.45 $\mu \mathrm{m}$ membrane. An aliquot of $20 \mu \mathrm{L}$ was injected into automatic amino acid analyzer and the samples were determined by comparing with standard peak areas.

Hydrolysis amino acids in samples were also determined. The diluent sample with approximately $12 \mathrm{mg}$ crude protein was placed in a $20 \mathrm{~mL}$ text tube and then added with $9 \mathrm{~mL}$ $\mathrm{HCl}(6 \mathrm{~mol} / \mathrm{L})$. The test tube was sealed up after blowing into the nitrogen and dried at $110^{\circ} \mathrm{C}$ for $22 \mathrm{~h}$. The cooled solution was placed in a flask with the volume of $100 \mathrm{~mL}$ and neutralized by $9 \mathrm{~mL} \mathrm{NaOH}(6 \mathrm{~mol} / \mathrm{L}) .0 .02 \mathrm{~mol} / \mathrm{L}$ of $\mathrm{HCl}$ was added to the flask until to the calibration tail. The solution filtered through a $0.45 \mu \mathrm{m}$ membrane and $20 \mu \mathrm{L}$ filtrate was injected into automatic amino acid analyzer to detect the hydrolysis amino acids ${ }^{16}$

Total sugar determination: Amount of sugars in rice wine was analyzed by colourimetric method, which called phenol-sulphuric acid method ${ }^{17}$. Samples were treated with dilutions of $10^{3} .20 \mathrm{~mL}$ of dilution sample was placed in a test tube and then added with $1 \mathrm{~mL}$ phenol and $5 \mathrm{~mL}$ sulphuric acid in proper order. The absorbance readings of each test tube were measured at $490 \mathrm{~nm}$ using a spectrophotometer.

Determination of monosaccharide and disaccharides in rice wines: Monosaccharide and disaccharides were measured by performing high-performance liquid chromatography (Agilent 1100 series) with a differential refractive index detector, using a chromatographic column (ZORBAX Carbonhydrate $4.6 \times 250 \mathrm{~mm} 5 \mu \mathrm{m})$. A thermostat was set at $30^{\circ} \mathrm{C}$. The mobile phase was methyl cyanide and water (in the ratio of 75:25 (v/v) methyl cyanide: water) at a flow rate of $1 \mathrm{~mL} / \mathrm{min}$. Samples were filtered though $0.22 \mu \mathrm{m}$ membrane filter before injection into the HPLC system and then $10 \mu \mathrm{L}$ each of samples was injected into volume for analyzing ${ }^{18}$. Sugar standards of Dsucrose, D-glucose, D-fructose, D-maltose and D-xylose were purchased from Aladdin Industrial Inc.

Statistical analysis: Data analysis was carried out with SPSS software (ver.16.0; SPSS, Chicago, IL). One-way ANOVA was used to determine significant differences between means at a significance level of $\alpha=0.05$.Tukey's test was used to perform multiple comparisons between means. All analyses were performed in triplicate $(n=3)$.

\section{RESULTS AND DISCUSSION}

Physico-chemical attribution in rice wine: As we discussed above, acidity and alcoholic content are the important index for evaluating the rice wine's quality. Solid content, the kinds of amino acids and monosaccharide represent the nutritious value of rice wine. In this study, we detected the total solid, acidity, $\mathrm{pH}$ value and alcoholic content in nine kinds of rice wines from different regions of China and from Table-1, we could see that the solid content in these rice wine ranged from $2.0435 \mathrm{~g} / 100 \mathrm{~mL}$ to $19.2735 \mathrm{~g} / 100 \mathrm{~mL}$. Three rice wine samples from Ningan province and the semi-solid sample X2 were the top four acidity samples and the highest acidity in these nine kinds of rice wine reached up to $1.05 \mathrm{~g} / 100 \mathrm{~mL}$. Acidity in the following samples were in turn with X1 > MDJ2 
TABLE-1

SOLID CONTENT, ACIDITY AND ALCOHOLIC CONTENT IN THE NINE KINDS OF RICE WINES( $\mathrm{x} \pm \mathrm{SD}, \mathrm{n}=3)$

\begin{tabular}{cccc}
\hline Sample & Solid content $(\mathrm{g} / 100 \mathrm{~mL})$ & Acidity $(\mathrm{g} / 100 \mathrm{~mL})$ & Ethanol content $(\%$ vol $)$ \\
\hline NA1 & $3.7930 \pm 0.0410^{\mathrm{c}}$ & $0.74 \pm 0.01^{\mathrm{g}}$ & $0.65 \pm 0.02^{\mathrm{f}}$ \\
NA2 & $4.0088 \pm 0.0473^{\mathrm{d}}$ & $1.05 \pm 0.01^{\mathrm{i}}$ & $3.3 \pm 0.4^{\mathrm{c}}$ \\
NA3 & $2.0435 \pm 0.1775^{\mathrm{a}}$ & $0.29 \pm 0.01^{\mathrm{a}}$ & $2.6 \pm 0.3^{\mathrm{b}}$ \\
MDJ1 & $4.0883 \pm 0.0117^{\mathrm{d}}$ & $0.52 \pm 0.01^{\mathrm{d}}$ & $1.9 \pm 0.2^{\mathrm{a}}$ \\
MDJ2 & $4.1047 \pm 0.0180^{\mathrm{d}}$ & $0.31 \pm 0.01^{\mathrm{b}}$ & $2.0 \pm 0.1^{\mathrm{a}}$ \\
FS1 & $2.2180 \pm 0.0005^{\mathrm{b}}$ & $0.55 \pm 0.01^{\mathrm{e}}$ & $5.1 \pm 0.3^{\mathrm{e}}$ \\
X1 & $13.3930 \pm 0.0070^{\mathrm{e}}$ & $0.81 \pm 0.02^{\mathrm{h}}$ & $3.0 \pm 0.1^{\mathrm{c}}$ \\
X2 & $19.2735 \pm 0.0585^{\mathrm{g}}$ & $0.44 \pm 0.01^{\mathrm{c}}$ & $4.3 \pm 0.1^{\mathrm{d}}$ \\
X3 & $18.2510 \pm 0.0250^{\mathrm{f}}$ & & \\
\hline a,b,c Means with different letters are significantly different, $\mathrm{p}<0.05$ & &
\end{tabular}

$>\mathrm{X} 3>\mathrm{FS} 1>\mathrm{MDJ} 1$ and have a significant difference between each other $(\mathrm{p}<0.05)$. The alcoholic content in the nine kinds of rice wines ranged from $1.9 \%$ (vol) to $5.1 \%$ (vol).

The result showed that there was higher solid content in three semi-solid rice wines from Xiaogan province than others and there were significant differences among the three samples. The two kinds of rice wines MDJ2 and MDJ1 from Mudanjiang province had similar solid contents and lower than the top of three. The sample NA3 from Ningan province had the lowest solid content in the nine kinds of rice wine. Solid content in rice wine contained ash, simple proteins, fat and sugars, etc., which endowed high nutritious value to rice wine. The sample FS1 had the highest alcoholic content and the two samples from Mudanjiang province had the lowest alcoholic contents with no significant difference $(\mathrm{p}<0.05)$.

Protein content: The protein content of rice wine was detected as Fig. 1 showed. The rice wine MDJ2 that contained $85.06 \mathrm{mg} / 100 \mathrm{~mL}$ protein and X3 that contained $82.22 \mathrm{mg} /$ $100 \mathrm{~mL}$ protein were the top of two samples of protein containing. There were no significant differences $(p<0.05)$ of protein content in FS1, X1 and X2, which determined as 61.70 $\mathrm{mg} / 100 \mathrm{~mL}, 55.51 \mathrm{mg} / 100 \mathrm{~mL}$ and $63.99 \mathrm{mg} / 100 \mathrm{~mL}$, respectively. The lowest protein contained samples were identified as NA1, NA2, NA3 and MDJ1, which determined as 43.63 $\mathrm{mg} / 100 \mathrm{~mL}, 44.53 \mathrm{mg} / 100 \mathrm{~mL}, 46.10 \mathrm{mg} / 100 \mathrm{~mL}$ and 47.98 $\mathrm{mg} / 100 \mathrm{~mL}$ and there were no significant differences $(\mathrm{p}<0.05)$ in these four samples.

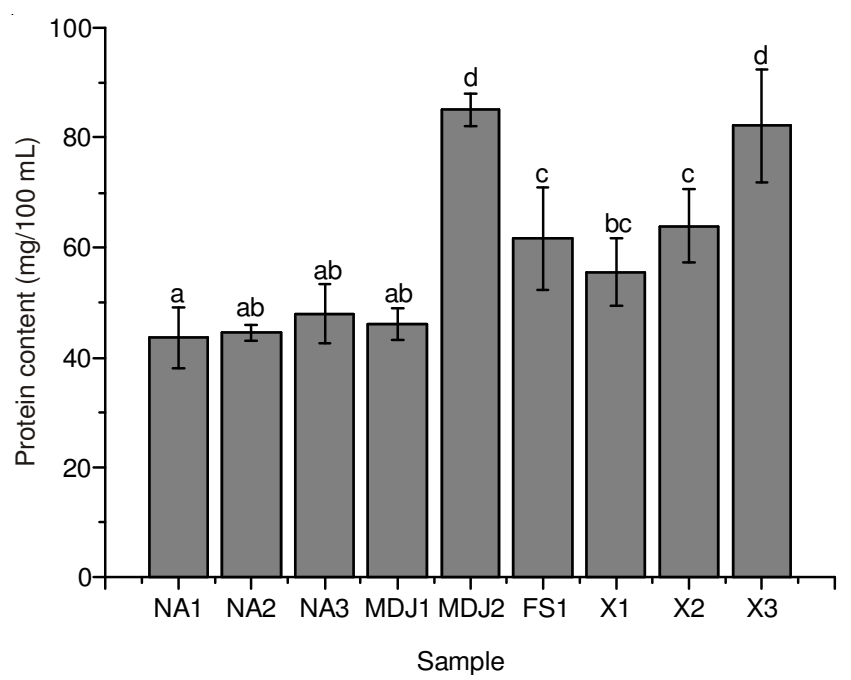

Fig. 1. Protein content in the nine kinds of rice wines a, b, c, d: Different letters indicate significant differences at $\mathrm{p}<0.05$
Acidity, alcoholic content, which were detected above and protein content had little dependency with the type of rice wine but had significant differences among rice wines with different classifications and places of origin, which may be caused by the quality decided factors that usually called raw materials, yeast strains, brewing conditions and maturation conditions ${ }^{19}$.

Analysis amino acids: Free amino acids and hydrolysis amino acids were determined by an amino acid analyzer. Free amino acids in nine kinds of rice wine was showed in Table- 2 . There were some limited amino acids in rice wines, but different in different rice wines. Isoleucine was absent in NA2 and MDJ2 rice wines. Valine, leucine and isoleucine were absent in MDJ1 sample. Tyrosine and arginine in FS1 sample were undetected, so did cysteine in $\mathrm{X} 2$ rice wine and histidine in X3 rice wine. Tryptophan, which was hydrolyzed in acid environment, was undetected in all samples, because acid hydrolyzation method was applied in this article. From Table-2 we could see the most abundant amino acids represented as proline, leucine, tyrosine, phenylalanine and alanine in different rice wines. The ratio of essential amino acids in these rice wine samples ranged from 7.24 to $54.57 \%$ and there were more than one sample with high ratio of $40 \%$. The X2 turned out to be the most essential amino acids containing sample.

The seventeen kinds of hydrolysis amino acids were also determined as showed in Table-2 and ranged from $17.90 \mathrm{mg} /$ $100 \mathrm{~mL}$ to $166.25 \mathrm{mg} / 100 \mathrm{~mL}$. Glutamate was the most abundant kind of amino acid in all nine kinds of samples and the content of this kind of amino acid was 3.52-31.49 mg/100 $\mathrm{mL}$. The essential amino acids calculated as hydrolysis amino acids ranged from 23.50 to $34.59 \%$. The total amino acid content of X2 rice wine, which is semi-solid sample, was served as the highest total amino acid content sample.

Thus, it is seen that the main free amino acid in nine kinds of rice wines are different. On the contrary, main hydrolysis amino acid was represented as glutamate identically, which corresponding with previous report ${ }^{11}$, possibly because Glutamate is the maximum kind of amino acid in rice which served as the raw material of rice wine.

Total sugar content: Total sugar content in nine kinds of rice wines was detected as showed in Fig. 2 and X2 sample represented as the highest total sugar contend sample with the value of $15.15 \mathrm{~g} / 100 \mathrm{~mL}$. Total sugar contents in rest of samples was $0.31-11.06 \mathrm{~g} / 100 \mathrm{~mL}$, from which we could see the sugar content in semi-solid samples was higher than liquid samples with significant differences $(\mathrm{p}<0.05)$. 
FREE AMINO ACIDS AND HYDROLYSIS AMINO ACIDS IN THE NINE KINDS OF DIFFERENT RICE WINES (mg/100 mL)

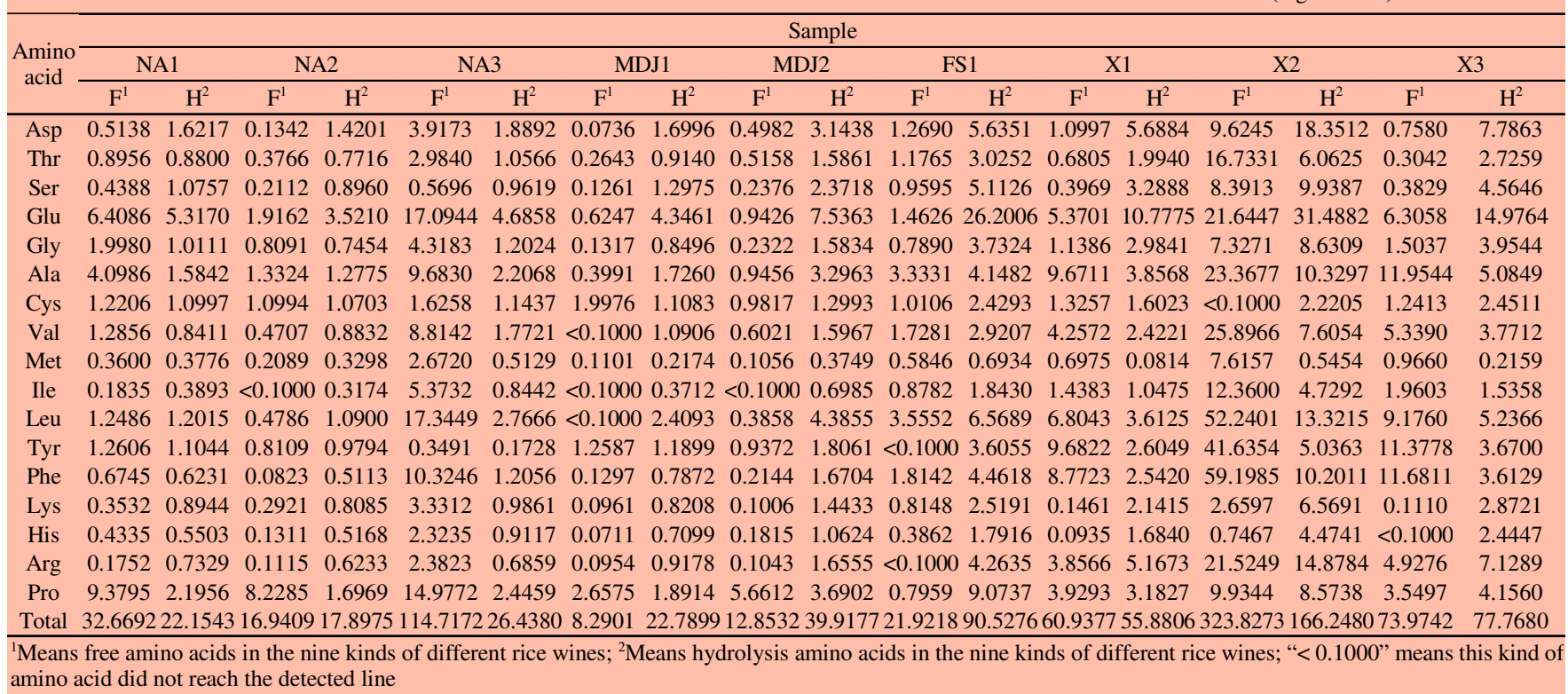

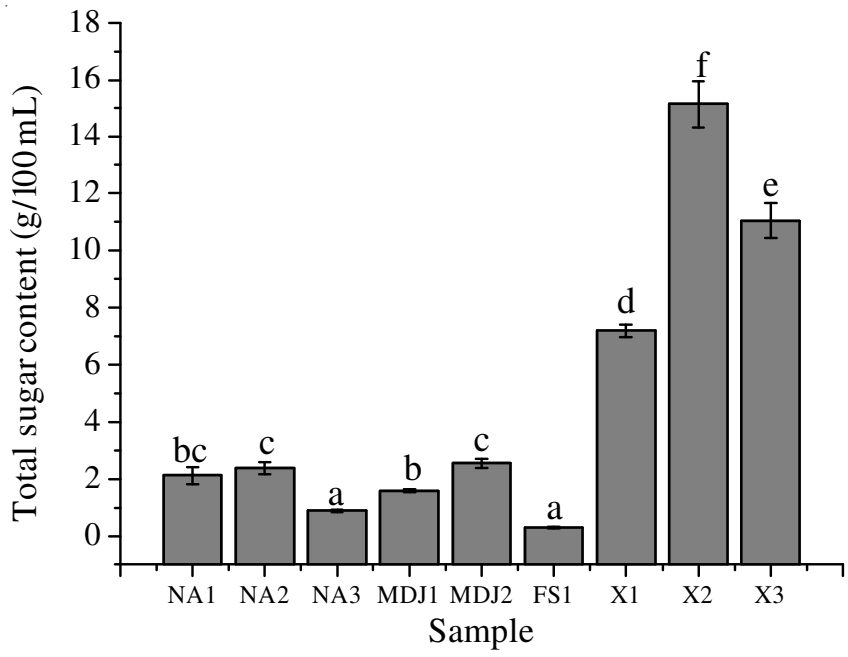

Fig. 2. Total sugar contents in nine kinds of rice wines, a, b, c, d, e, f: Different letters indicate significant differences at $\mathrm{p}<0.05$

Solid content detected above and total sugar content in nine kinds of rice wines tended to be relative with type of rice wine. Solid content and total sugar was higher in semi-solid samples than liquid samples and there was significant difference between each other.

Monosaccharide and disaccharide: Five kinds of monosaccharide and disaccharide were determined by HPLC method. Sugar standards were run through the column and the spectrogram showed in Fig. 3. There were different kinds of monosaccharide and disaccharide in different kinds of rice wines. HPLC spectrogram of X1 rice wine sample was showed in Fig. 4 (spectrogram of the rest of samples were not showed). Glucose, which ranged from $0.05 \mathrm{~g} / 100 \mathrm{~mL}$ to $16.59 \mathrm{~g} / 100 \mathrm{~mL}$, was discovered in eight kinds of rice wines except FS1 sample as showed in Table-3. Sucrose was found in NA2 and MDJ2 samples and fructose was found in X1 sample. Besides, maltose was found in three semi-solid samples. Fructose was absent in all nine kinds of rice wines. Five kinds of sugar in FS1 sample were not touched the detecting underline.

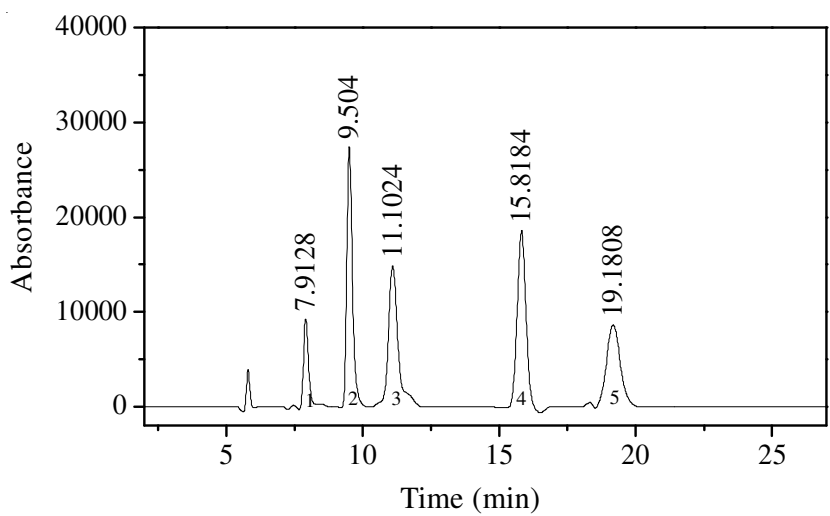

Fig. 3. Spectrogram of standard monosaccharide and disaccharides, 1-xylose, 2-fructose, 3-glucose, 4-sucrose, and 5-maltose

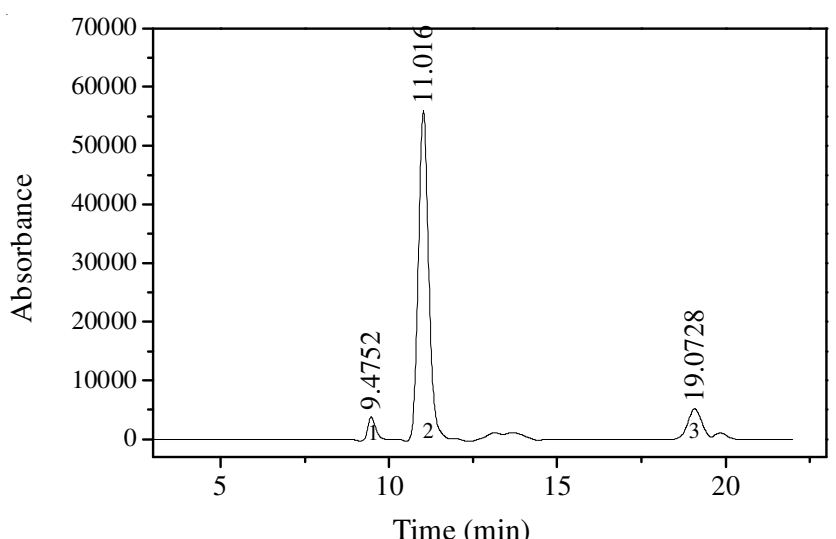

Fig. 4. Spectrogram of monosaccharide and disaccharides in $\mathrm{X} 1$ rice wine sample, 1-fructose, 2-glucocose, and 3-maltose

Starch in rice as the raw material of rice wine broken down to the monosaccharide and disaccharides, such as glucose, fructose, maltose, etc., which were also found in Yong's research ${ }^{20}$. Five kinds of monosaccharide and disaccharides were determined in this paper and found that the kinds of sugar were different in different samples. The kinds of sugar in rice wine may have relationships with the microflora in rice wine. 


\begin{tabular}{cccccc}
\hline \multicolumn{6}{c}{ TABLE-3 } \\
\multicolumn{5}{c}{ AMOUNT OF FIVE KINDS OF MONOSACCHARIDE } \\
AND DISACCHARIDES IN RICE WINES (g/100 mL) \\
\hline Sample & D & D & D & D & D \\
& - xylose & -fructose & -glucose & -sucrose & -maltose \\
\hline NA1 & - & - & 0.17 & - & - \\
NA2 & - & - & 0.05 & 0.07 & - \\
NA3 & - & - & 0.22 & - & - \\
MDJ1 & - & - & 0.09 & - & - \\
MDJ2 & - & - & 0.10 & 0.19 & - \\
FS1 & - & - & - & - & - \\
X1 & - & 0.11 & 1.53 & - & 0.27 \\
X2 & - & - & 16.59 & - & 0.27 \\
X3 & - & - & 4.45 & - & 0.85 \\
\hline “-”Means this kind of monosaccharide undetected
\end{tabular}

\section{Conclusion}

The results indicated that rice wine is full of nutritious gradients, which is different in different rice wines. This paper provided a basic research for better understanding the relationships between the physico-chemical attributes, nutritional ingredients and environmental conditions. Furthermore, these findings could be a guide to produce more nutritional and delicious rice wines. More researches need to be conducted on rice wine because of its nutritional potential and multipurpose use.

\section{ACKNOWLEDGEMENTS}

This work was supported by Technology of the People's Republic of China (2007AA10Z354).

\section{REFERENCES}

1. X.C. Lv, Z.Q. Huang, W. Zhang, P.F. Rao and L. Ni, J. Gen. Appl. Microbiol., 58, 33 (2012).

2. S.J. Rhee, J.E. Lee and C.H. Lee, Microb. Cell Fact., 10(Suppl 1), S5 (2011).

3. H.R. Kim, J.H. Kim, D.H. Bae and B.H. Ahn, J. Microbiol. Biotechnol, 20, 1702 (2010).

4. J. Jin, S.Y. Kim, Q. Jin, H.J. Eom and N.S. Han, J. Microbiol. Biotechnol., 18, 1678 (2008).

5. K. Jeyaram, W.M. Singh, A. Capece and P. Romano, Int. J. Food Microbiol, 124, 115 (2008).

6. N.T.P. Dung, F.M. Rombouts and M.J.R. Nout, Food Microbiol., 23, 331 (2006).

7. T. Uno, A. Itoh, T. Miyamoto, M. Kubo, K. Kanamaru, H. Yamagata, Y. Yasufuku and H. Imaishi, J. Inst. Brew., 115, 116 (2009).

8. Z. Xianfeng, Y. Shengyu and Z. Pengpai, Food Sci. Technol., 1, 77 (2005).

9. Z. Haibo, Z. Yan and C. Shaofeng, Food Sci. Technol., 7, 203 (2007).

10. F. Shen, X.Y. Niu, D.T. Yang, Y. Ying, B. Li, G. Zhu and J. Wu, J. Agric. Food Chem., 58, 9809 (2010).

11. H. Yu, Y.S. Ding and S.F. Mou, Chromatographia, 57, 721 (2003).

12. J.Y. Kim, D. Kim, P. Park, H.I. Kang, E.K. Ryu and S.M. Kim, Food Chem., 128, 87 (2011).

13. J.W. Jeong, P.W. Nam, S.J. Lee and K.G. Lee, J. Agric. Food Chem., 59, 7039 (2011).

14. X.L. Mo, Y. Xu and W.L. Fan, J. Agric. Food Chem., 58, 2462 (2010).

15. M.M. Bradford, Anal. Biochem., 72, 248 (1976).

16. W. Danjing, C. Miaofen and Q. Yonghong, Pharmaceut. Care Res., 6, 212 (2006).

17. M. Dubois, K.A. Gilles, J.K. Hamilton, P.A. Rebers and F. Smith, Anal. Chem., 28, 350 (1956).

18. J. Pazourek, J. Sep. Sci., 33, 974 (2010)

19. S.A. Chen and Y. Xu, J. Inst. Brew., 116, 190 (2010).

20. Y. Yong, C. Weiping, M. Rui and Y. Lili, China Brewing, 231, 182 (2011). 